\title{
Association Between Blood Pressure And Lung Function In Chinese Children: The Seven Northeastern Cities Study
}

Da Huo

Weifang People's Hospital

Mo Yang

University of Eastern Finland

Qi-Zhen Wu

Sun Yat-sen University

Caroline J Lodge

The University of Melbourne

Jennifer L Perret

The University of Melbourne

Dinh S Bui

The University of Melbourne

Shyamali C Dharmage

The University of Melbourne

\section{Pasi Jalava}

University of Eastern Finland

Qiang Hu

Weifang People's Hospital

Guang-Hui Dong ( $\sim$ donggh512@hotmail.com )

Sun Yat-sen University

\section{Research Article}

Keywords: Lung function, Hypotension, Hypertension, Chinese Children

Posted Date: December 30th, 2021

DOI: https://doi.org/10.21203/rs.3.rs-1209933/v1

License: (c) (1) This work is licensed under a Creative Commons Attribution 4.0 International License.

Read Full License 


\section{Abstract}

Background: A global increase in asthma and COPD incidence has occurred, the cause is unknown. One potential relationship that has yet to be explored is the interaction between blood pressure (BP) and lung function in children 5-17 years old. Our purpose is to assess the relationship between hypotension, hypertension, and lung function in children 5 to 17 years old.

Methods: Participants were recruited from elementary and middle schools from 7 cities in northeastern China $(N=6,797)$. BP was categorized into 3 groups: hypotensive $\left(<5^{\text {th }}\right.$ percentile or $<90 \mathrm{mmHg}$ if children $>10$ years), normotensive and hypertensive ( $>95^{\text {th }}$ percentile) based on American Academy of Pediatrics standards. Spirometry measured lung function in forced vital capacity (FVC), forced expiratory volume in 1 second (FEV1), peak expiratory flow (PEF), and maximum mid expiratory flow (MMEF). Associations were assessed using logistic regression analysis.

Results: Decreases in FVC , FEV1, PEF, and MMEF were noted in hypotensive children. Higher FVC, FEV1, $\mathrm{PEF}$, and MMEF were noted among children ${ }^{3} 10$ with hypertension, while children $<10$ years, only had increased FVC compared to normotensive children. Statistically significant interactions between hypotension and PEF < 75\% (OR:2.31; 95\% Cl: 1.17-4.23), were seen for children < 10 years.

Conclusions: Our findings suggest that, in this study population, hypotension may be associated with decreased lung function, and the increased lung function may be associated with hypertension in children. Future studies are needed to confirm temporality as this is the first study to explore these relationships in children which requires in depth investigation.

\section{What Is The Key Question?}

Is there any association between hypotension, hypertension, and lung function in children 5 to 17 years old?

\section{What is the bottom line?}

Our study of children provides evidence suggesting adverse effects of decreased lung function on hypotension and increased lung function on hypertension.

\section{Why read on?}

Our findings suggest that Hypotension may be associated with decreased lung function, and the increased lung function may be associated with hypertension in children. This is the first study to explore these relationships in children which requires in depth investigation.

\section{Background}


A child's lung development is imperative to quality of life, as it starts from birth and continues until school age[1, 2]. Lung function is an objective indicator for the diagnosis of respiratory diseases[3], such as chronic obstructive pulmonary disease (COPD)[4] and asthma[5]. Poor lung function is often characteristic of many respiratory conditions such as wheezing, chronic obstructive pulmonary disease, asthma, bronchopulmonary dysplasia, and many others[6, 7]. These are often residuals from poor lung development during childhood and studies have shown that poor lung function in childhood can affect the onset of these diseases later in life[7]. Therefore, obtaining the data of childhood lung function is very useful for the subsequent assessment and diagnosis of respiratory diseases[8].

Hypertension is a high incidence disease among children worldwide, the pooled hypertension and prehypertension prevalence were about $4.00 \%$ and $9.67 \%[9]$. Hypertension is also a childhood disease that can affect the rest of the child's life if left untreated[10]. Children with persistently high or persistently low blood pressure may be more prone to have similar health problems due to this altered state[10, 11]. In 2015, more than 1 billion adults worldwide were living with hypertension[12, 13]. Previous pathophysiologic and epidemiologic study evidences have suggested that childhood hypertension was related to essential hypertension in adulthood and harmful lifelong cardiovascular events[14]. Therefore, reliable estimates of the level of childhood blood pressure serve as the basis for disease prevention and treatment[9].

There is only one study investigated the association between lung function and blood pressure across different ages including 727 newborns, 382 5-year old children and 6,722 adults aged 18-91 years which indicated positive associations between lung function and blood pressure in individuals $<40$-year old[15]. A lot studies that have assessed the prevalence of hypertension in children and adolescents[16, 17], and many studies have looked at the relationship between weight, BMI, waist circumference, percent body fat, and hypertension on lung function[18-20]. However, there is a scarcity of evidence on the early symptoms of hypo- and hypertension on children's lung function. To our knowledge, there are no studies that have looked at this interaction in children age 5 to 17. The objective of this study was to determine the relationship between hypotension, hypertension and lung function in children age 5 to 17 from 7 cities in Northeastern China.

\section{Methods}

\section{Study participant selection}

We conducted a large population based cross-sectional study in northeastern China called the seven northeastern cities study (SNEC). This study has been used in multiple studies previously and further details on study methods and participant recruitment can be found in these studies[21-23]. Briefly, one elementary and one middle school within $2 \mathrm{~km}$ radius of air monitoring sites were randomly selected from the 24 districts and 62 schools were included in our study. We selected 1-2 classes from each grade within each school in each school. All participants must have lived in the study district for at least 2 years and had resided within $2 \mathrm{~km}$ radius from the air quality monitoring station were eligible. The random 
sampling process is described in detail in eMethods 1 in the Supplement. Before the start of the study, an information session was conducted for study participants, teachers to give clear information about this study. Teachers described the study to the parent, informed consent was obtained during this information session, and distributed questionnaires to the parent with return envelopes. Eligible students' parent could choose to complete the study questionnaire in the school or at home and return it in the next day and in a sealed envelope. Teachers should not encourage or force parents to participate. The content of the study questionnaire was previously described by our group[24], including sociodemographic factors, lifestyle factors, residential factors, personal medical history, including a detailed history of respiratory health, and family medical history among other requested information. Trained nurses were followed the standardized of World Health Organization protocol to measure students' height (at $0.1 \mathrm{~cm})$ and weight (at $0.1 \mathrm{~kg}$ ) of and calculated the body mass index (BMI) in $\mathrm{kg} / \mathrm{m}^{2}$. We dichotomized the education of parents as having high school education or not, and categorized annual income from family ( $\leq 4999$, $5000-9999,10000-29999,30000-100000$, or $>100000$ RMB). Students' passive tobacco smoke exposure was defined as living with a daily cigarette smoker. Home coal use was assessed as household use for cooking or space heating. We defined family history of atopy as a clinical diagnosis of allergies. We determined home renovation as a positive response to the question "Have you made any renovations in your home within the past two years?" We determined low birth weight as the birth weight is less than $2500 \mathrm{~g}$, premature birth as the age of less than 37 weeks at birth. We defined breastfeeding as having been mainly breast fed for more than three months. A detailed description of questionnaire information is described in eMethods 2 in the Supplement. Completed questionnaires were returned to the teachers via the child. We recruited 7,326 participants with a total of 7,109 (97\%) participants responding to the survey and allowing for blood pressure and lung function measurements. 6,797 participants were included for the final analysis after removing participants who had lived less than 2 years in the district and those with missing data[22, 25]. The study was approved by the Human studies committee of Sun Yat-sen university using ethics approval code 026 with all of the requirements for protection of human subjects being met in accordance with the World Medical Association Declaration of Helsinki-Ethical Principles. Before starting to collect data, written informed consent from all participants and their parents/guardians was required.

\section{Blood pressure measurement}

We recorded all blood pressure measurements in accordance with the American Academy of Pediatrics methods (Falkner \& Daniels, 2004). We used standardized mercury sphygmomanometers to measure blood pressure after study participants had rested and sat in a temperate room for $5 \mathrm{~min}$. Trained nurses were asked to measure blood pressure in triplicate at two-minute intervals. An average of all three measurements was used and classified into subgroups: Hypotensive, Normotensive, and hypertensive. Pediatric hypotension (children $<10$ years) was defined as systolic and diastolic BP below the $5^{\text {th }}$ percentile for mean age and gender[10, 25]. For children ${ }^{3} 10$ years, hypotension was defined as systolic BP below $90 \mathrm{mmHg}$. Hypertension was defined as systolic blood pressure and diastolic blood pressure ${ }^{3}$ $95^{\text {th }}$ percentile based on mean age, gender and height on 3 separate occasions[26]. 


\section{Lung function measurement}

We recorded lung function measurements in accordance with standards of the American Thoracic Society (ATS) and European Respiratory Society (ERS). Trained staff used portable spirometers (MIR, Italy, Spirolab) to measure forced vital capacity (FVC), forced expiratory volume in $1 \mathrm{sec}$ (FEV1), peak expiratory flow (PEF), and maximum mid expiratory flow (MMEF) of the study participants. Study participants were given clear instructions on how to perform the forced respiratory maneuvers and care was taken to ensure that the participants understood them before spirometric testing. The examination was conducted in a quiet and comfortable room. Impairment in lung function was defined in previous literature as FVC $<85 \%$, FEV1 $<85 \%$, PEF $<75 \%$, MMEF $<75 \%$ of the predicted value for each patient. Dichotomous analysis was conducted using decreased or normal metrics[21, 23, 27]. Detailed lung function methods are further described in our previous study[21, 23].

\section{Statistical analysis}

Data was assessed for normality using the Shapiro-Wilkes W tests and homogeneity was detected through the Bartlett test for unequal variances. $T$ and $c^{2}$ tests were used to test for associations between continuous variables and categorical variables respectively. The interaction between blood pressure and lung function were determined using unconditional logistic regression and we used Student Newman Keuls - test to compare the mean lung function differences between hypotensive, normotensive and hypertensive individuals. Regressions were modeled to determine relationships within exposures using absolute change values. We adjusted the results for age as an effect modifier, and for confounders including parental education, breast feeding, low birth weight, premature birth, exercise per week, family income, parents as responders, home renovation, use of domestic cooking and heating fuels, environmental tobacco smoke exposure, family history of asthma and hypertension, and study districts. All analyses used p-values $<0.05$ to determine statistical significance[25]. We performed statistical analysis using SAS 9.4 (SAS Institute Inc., Cary, NC, USA).

\section{Results}

\section{Study population Characteristics}

Table 1 demonstrates the characteristics of the participants in our study. We subdivided the data into children $<10$ years and children ${ }^{3} 10$ years based on statistically significant differences. The mean age of the 1,764 children $<10$ years old was 8.89 and 5,033 children ${ }^{3} 10$ years was 12.50 years old. The mean SBP in the total sample was 112.50 (95\% confidence intervals, Cl: $12.46-12.54) \mathrm{mmHg}$; for children < 10 years old the mean SBP was 106 (95\% Cl: 105.5 - 106.5) mmHg and for children ${ }^{3} 10$ years it was 114.79 (95\% Cl: 114.4 - 115.2) $\mathrm{mmHg}$. The DBP was similar among both age groups of children. Lung function was noted to be higher in children who were ${ }^{3} 10$ years old. Those with higher SBP and DBP were more likely to have higher FVC, FEV1, PEF, and MMEF. 
The mean lung function of children $<10$ years old and ${ }^{3} 10$ years old based on blood pressure status of hypotension, hypertension, and normotension are displayed in table 2. Those with hypertension status have higher FVC, FEV1, PEF, and MMEF than those with normotension. For children < 10 years old statistical significance is seen for FVC $(P<0.0001)$, FEV1 $(P=0.0005)$, and PEF $(P=0.0192)$. While for children ${ }^{3} 10$ years old, this significance is seen in all four lung function groups.

\section{Associations between hypertension, hypotension and lung function measures}

Table 3 shows the interaction between hypertension and hypotension on lung function with OR and $95 \%$ $\mathrm{Cl}$ stratified by age. Compared to the referent group, or those who are classified as normotensive, it appears that children $<10$ years old and hypotensive had reduce $P E F$ function $(O R=2.31,95 \% \mathrm{Cl}=1.17$ 4.23). The interactions between hypertension and hypotension on other lung function indicators did not appear to be statistically significant when stratified by age.

The absolute change estimates for lung function based on hypertension and hypotension status are displayed in table 4 . The change estimates showed statistically significant interactions between all four lung function categories with hypotension in children in both age categories showing decreased lung function $(P £ 0.01)$. For hypertension there were statistically significant interactions for increased lung function in all four lung function groups for children ${ }^{3} 10$ years old $(P=0.001)$. While those $<10$ years old appear to only have statistically significant interactions on FVC $(P=0.0001)$ and FEV1 $(P=0.0001)$.

Supplemental tables are provided which show associations between systolic and diastolic blood pressure (Table S1), stratification and associations based on gender (Table S2, S3) and plots of the relationship between lung function and systolic blood pressure (Figure S1). Plots indicate a strong interaction between lung function and systolic blood pressure due to age (Figure S1). Sensitivity analysis indicated that age was a stronger modifying factor for lung function than gender.

\section{Discussion}

We conducted a large population based cross-sectional study among 6,797 children in which we explored the cross-sectional relationship between blood pressure and lung function. We found that in children $<10$ years old, hypotension may be associated with decreased PEF. We also determined that increased lung function may be related to hypertension and decreased lung function may be associated with hypotension. Our results were consistent between age group, sex, and income categories.

In our study population, the prevalence of hypotension was $2.80 \%$, which is on par with other reports. The prevalence of hypertension in our study was $13.17 \%$ which is also consistent with other prevalence studies ranging from $3.2 \%$ to $19.4 \%[26,28]$. The findings in our analysis are counter to studies looking at adult lung response to hypertension, which may be due to the age difference in the populations. A study conducted among 2,607 participants older than 30 years old residing in Fujian, China identified metabolic syndrome (OR: $4.623,95 \% \mathrm{Cl}: 3.626,5.894)$, which includes high blood pressure, as a risk factor for decreased lung function[29]. In a population-based study among 1,319 adults aged 40 to 65 years old, 
high blood pressure was associated with lowered FEV1 $(P=0.04)$ and FVC $(P=0.01)[30,31]$. Other studies have even found that metabolic syndrome and blood pressure may be more important factors than obesity in determining lung function[32]. Multiple studies have demonstrated an association between hypertension and reduced lung function, however, in all of those studies the temporal relationship between these factors is unclear. In children, hypertension is also an ever-increasing problem. A cross-sectional study conducted among $6,79011-17$ year-old children, $15.7 \%$ were recognized to have pre-hypertension and $3.2 \%$ of the children were recognized to have hypertension which may lead to risk of heart disease and organ damage[26]. Despite lower prevalence of hypotension, it may be equally as important in development as hypertension[10,33].

In general, increased cardiac output is understood to elevate blood pressure, however this interaction with lung function and other interfering factors may make it difficult to determine an association[11, 34]. Hypertension in young adults may be due to either increased stroke volume or peripheral vascular resistance[35]. Increasing cardiac output has been seen to have effects on pulmonary blood flow which may be why there are associations seen between lung function and blood pressure[36]. Increased numbers of circulating cytokines appear to enhance maturation of the lung which occurs simultaneously with blood vessel development[37]. Although a neonate is born with a functioning lung, alveolar septation and multiplication does not take place until 36 weeks to 2 years after birth. The enlargement of terminal bronchioles and alveoli does not take place until 18 to 22 years of age which can allow for alteration by other body systems during this period[1, 37, 38]. The above developmental factors indicate a strong relationship between lung development and vascular development which would allow for strong interactions between these two systems $[1,37,39,40]$. However, all these factors make the interaction between these two biological responses difficult to parse out[18, 28].

Our study also includes limitations that should be taken into consideration while interpreting the results. First, due to the cross-sectional nature of the study we were unable to determine temporality for exposure and outcome groups. We were also only able to use non-invasive method to determine blood pressure and could not determine pulmonary artery pressure. Further, in using a questionnaire, we were unable to reduce response bias, thus selection bias may have occurred in the recruitment process. Prospective studies are vital to determine the temporality of the relationship and further assess the association. Despite the limitations in our study, the important strengths of our research should still be considered. Both our exposure and outcome variables were measured by trained professionals and ensured for precision of the estimates. In addition, our study has a large sample size with a $97 \%$ response rate which allowed for increased statistical power. Finally, we were able to minimize information bias by providing generalized information about the study objectives to participants.

\section{Conclusions}

In conclusion, our study has found that hypotension in Chinese children ages 5 to 17 years old is associated with impairment in lung function while hypertension is associated with a slight increase in lung function for children 10 to 17 years old. To the best of our knowledge, our study is the first to assess 
both hypotension and hypertension effects on lung function in children 5 to 17 years old. Future studies are needed to determine temporality for this association, physiological or pathological causes of blood pressure, and underlying mechanisms for the association. This study adds to current knowledge about blood pressure and lung function and provides a resource for future endeavors.

\section{Abbreviation Definition List}

COPD: chronic obstructive pulmonary disease; BP: blood pressure; FVC: forced vital capacity FEV1: forced expiratory volume in 1 second; PEF: peak expiratory flow; MMEF: maximum mid expiratory flow; BMI: body mass index; SNEC: study in northeastern China called the seven northeastern cities; RMB: Chinese yuan; ATS: American Thoracic Society; ERS: European Respiratory Society; Cl: confidence intervals; OR: adds ratio.

\section{Declarations}

\section{Acknowledgments}

We thank all authors for their contributions to the article.

\section{Authors' contributions}

Study concept and design: G-HD, QH. Acquisition of data: G-HD, QH, DH, MY. Analysis and interpretation of data: DH, MY, Q-ZW, QH, G-HD. Drafting of the manuscript: DH, MY, PJ, QH, G-HD. Critical revision of the manuscript for important intellectual content: all authors. Statistical analysis: DH, MY, G-HD. Obtained funding: G-HD.

\section{Funding}

This work was supported by the National Natural Science Foundation of China (grant numbers 81872583, 81872582, and 81972992), the National Key Research and Development Program of China (grant numbers 2018YFE0106900 and 2018YFC1004300), the Guangdong Provincial Natural Science Foundation Team Project (grant number 2018B030312005), the Science and Technology Planning Project of Guangdong Province (grant numbers 2019A050510017 and 2018B05052007), the Science and Technology Planning Project of Guangzhou (grant numbers 201803010054 and 201807010032), the Fundamental Research Funds for the Central Universities (grant number 19ykjc01), and Science and Technology Program of Zhongshan (grant number 2019B1110). The sponsor or funding organization had no role in the design or conduct of this research.

\section{Availability of data and materials}

The datasets used and/or analysed during the current study are available from the corresponding author on reasonable request 
Ethics approval and consent to participate

The study was approved by the Human studies committee of Sun Yat-sen university using ethics approval code 026 with all of the requirements for protection of human subjects being met in accordance with the World Medical Association Declaration of Helsinki-Ethical Principles. Before starting to collect data, written informed consent from all participants and their parents/guardians was required.

\section{Consent for publication}

Not applicable.

Competing interests

None declared.

\section{References}

1. Burri PH: Structural aspects of postnatal lung development-alveolar formation and growth. Neonatology 2006, 89:313-322.

2. Owens L, Laing I, Zhang G, Le Souef P: Early sensitization is associated with reduced lung function from birth into adulthood. Journal of Allergy and Clinical Immunology 2016, 137:1605-1607. e1602.

3. Vos T, Abajobir AA, Abate KH, Abbafati C, Abbas KM, Abd-Allah F, Abdulkader RS, Abdulle AM, Abebo TA, Abera SF: Global, regional, and national incidence, prevalence, and years lived with disability for 328 diseases and injuries for 195 countries, 1990-2016: a systematic analysis for the Global Burden of Disease Study 2016. The Lancet 2017, 390:1211-1259.

4. Halpin DM, Decramer M, Celli BR, Mueller A, Metzdorf N, Tashkin DP: Effect of a single exacerbation on decline in lung function in COPD. Respiratory medicine 2017, 128:85-91.

5. O'Byrne PM, Pedersen S, Lamm CJ, Tan WC, Busse WW: Severe exacerbations and decline in lung function in asthma. American journal of respiratory and critical care medicine 2009, 179:19-24.

6. Fawke J, Lum S, Kirkby J, Hennessy E, Marlow N, Rowell V, Thomas S, Stocks J: Lung function and respiratory symptoms at $\mathbf{1 1}$ years in children born extremely preterm: the EPICure study. American journal of respiratory and critical care medicine 2010, 182:237-245.

7. Stern DA, Morgan WJ, Wright AL, Guerra S, Martinez FD: Poor airway function in early infancy and lung function by age 22 years: a non-selective longitudinal cohort study. The Lancet 2007, 370:758-764.

8. Agusti A, Faner R: Lung function trajectories in health and disease. The Lancet Respiratory Medicine 2019, 7:358-364. 
9. Song P, Zhang Y, Yu J, Zha M, Zhu Y, Rahimi K, Rudan I: Global prevalence of hypertension in children: a systematic review and meta-analysis. JAMA pediatrics 2019, 173:1154-1163.

10. Banker A, Bell C, Gupta-Malhotra M, Samuels J: Blood pressure percentile charts to identify high or low blood pressure in children. BMC pediatrics 2016, 16:1-7.

11. Park C, Fraser A, Howe LD, Jones S, Davey Smith G, Lawlor DA, Chaturvedi N, Hughes AD: Elevated blood pressure in adolescence is attributable to a combination of elevated cardiac output and total peripheral resistance: evidence against a hyperkinetic state. Hypertension 2018, 72:1103-1108.

12. Zhou B, Bentham J, Di Cesare M, Bixby H, Danaei G, Cowan MJ, Paciorek CJ, Singh G, Hajifathalian K, Bennett JE: Worldwide trends in blood pressure from 1975 to 2015: a pooled analysis of 1479 populationbased measurement studies with 19. 1 million participants. The Lancet 2017, 389:37-55.

13. Mills KT, Bundy JD, Kelly TN, Reed JE, Kearney PM, Reynolds K, Chen J, He J: Global disparities of hypertension prevalence and control: a systematic analysis of population-based studies from 90 countries. Circulation 2016, 134:441-450.

14. Raitakari OT, Juonala M, Kähönen M, Taittonen L, Laitinen T, Mäki-Torkko N, Järvisalo MJ, Uhari M, Jokinen E, Rönnemaa T: Cardiovascular risk factors in childhood and carotid artery intima-media thickness in adulthood: the Cardiovascular Risk in Young Finns Study. Jama 2003, 290:2277-2283.

15. Eising JB, van der Ent CK, van der Gugten AC, Evelein AM, Uiterwaal CS: The Association Between Lung Function And Blood Pressure Across Different Ages. In A103 HEALTH SERVICES RESEARCH AND ADMINISTRATIVE DATABASES. American Thoracic Society; 2012: A2309-A2309

16. Noubiap JJ, Essouma M, Bigna JJ, Jingi AM, Aminde LN, Nansseu JR: Prevalence of elevated blood pressure in children and adolescents in Africa: a systematic review and meta-analysis. The Lancet Public Health 2017, 2:e375-e386.

17. Akbari M, Moosazadeh M, Ghahramani S, Tabrizi R, Kolahdooz F, Asemi Z, Lankarani KB: High prevalence of hypertension among Iranian children and adolescents: a systematic review and metaanalysis. Journal of hypertension 2017, 35:1155-1163.

18. Margretardottir OB, Thorleifsson SJ, Gudmundsson G, Olafsson I, Benediktsdottir B, Janson C, Buist AS, Gislason T: Hypertension, systemic inflammation and body weight in relation to lung function impairment-an epidemiological study. COPD: Journal of Chronic Obstructive Pulmonary Disease 2009, 6:250-255.

19. Dixon AE, Peters U: The effect of obesity on lung function. Expert review of respiratory medicine 2018, 12:755-767.

20. Feng K, Chen L, HAN SM, ZHU GJ: Ratio of waist circumference to chest circumference is inversely associated with lung function in Chinese children and adolescents. Respirology 2012, 17:1114-1118. 
21. Yang M, Guo Y-M, Bloom MS, Dharmagee SC, Morawska L, Heinrich J, Jalaludin B, Markevychd I, Knibbsf LD, Lin S: Is PM1 similar to PM2. 5? A new insight into the association of PM1 and PM2. 5 with children's lung function. Environment International 2020, 145:106092.

22. Dong G-H, Ren W-H, Wang D, Yang Z-H, Zhang P-F, Zhao Y-D, He Q-C: Exposure to secondhand tobacco smoke enhances respiratory symptoms and responses to animals in $\mathbf{8 , 8 1 9}$ children in kindergarten: results from 25 districts in northeast China. Respiration 2011, 81:179-185.

23. Hu L-W, Yang M, Chen S, Shah K, Hailegiorgis Y, Burgens R, Vaughn M, Huang J, Xaverius P, Paul G: Effects of in utero and postnatal exposure to secondhand smoke on lung function by gender and asthma status: the Seven Northeastern Cities (SNEC) Study. Respiration 2017, 93:189-197.

24. Zeng X-W, Vivian E, Mohammed KA, Jakhar S, Vaughn M, Huang J, Zelicoff A, Xaverius P, Bai Z, Lin S: Long-term ambient air pollution and lung function impairment in Chinese children from a high air pollution range area: The Seven Northeastern Cities (SNEC) study. Atmospheric Environment 2016, 138:144-151.

25. Dong G-H, Qian ZM, Trevathan E, Zeng X-W, Vaughn MG, Wang J, Zhao Y, Liu Y-Q, Ren W-H, Qin X-D: Air pollution associated hypertension and increased blood pressure may be reduced by breastfeeding in Chinese children: the Seven Northeastern Cities Chinese Children's Study. International journal of cardiology 2014, 176:956-961.

26. McNiece KL, Poffenbarger TS, Turner JL, Franco KD, Sorof JM, Portman RJ: Prevalence of hypertension and pre-hypertension among adolescents. The Journal of pediatrics 2007, 150:640-644. e641.

27. Ma Y-N, Wang J, Dong G-H, Liu M-M, Wang D, Liu Y-Q, Zhao Y, Ren W-H, Lee YL, Zhao Y-D: Predictive equations using regression analysis of pulmonary function for healthy children in Northeast China. PloS one 2013, 8:e63875.

28. Sorof JM, Lai D, Turner J, Poffenbarger T, Portman RJ: Overweight, ethnicity, and the prevalence of hypertension in school-aged children. Pediatrics 2004, 113:475-482.

29. Chen YS, Li XQ, Li HR, Yu XL, Lu FF, Huang LP, Miao Y, Wang GQ, Lin X, Lian SQ: Spirometric prediction equations and the relationship between metabolic syndrome and spirometric parameters from an island in F ujian, C hina. The clinical respiratory journal 2017, 11:514-523.

30. Schnabel E, Karrasch S, Schulz H, Gläser S, Meisinger C, Heier M, Peters A, Wichmann H-E, Behr J, Huber RM: High blood pressure, antihypertensive medication and lung function in a general adult population. Respiratory research 2011, 12:1-8.

31. Schnabel E, Nowak D, Brasche S, Wichmann H-E, Heinrich J: Association between lung function, hypertension and blood pressure medication. Respiratory medicine 2011, 105:727-733. 
32. Lee HY, Yang HK, Song HJ, Chang HJ, Kang JY, Lee SH, Han S, Kim YK: Metabolic health is more closely associated with decrease in lung function than obesity. PloS one 2019, 14:e0209575.

33. van Albada ME, Schoemaker RG, Kemna M, Cromme-Dijkhuis AH, van Veghel R, Berger RM: The role of increased pulmonary blood flow in pulmonary arterial hypertension. European Respiratory Journal 2005, 26:487-493.

34. Sakhamuri S, Lutchmansingh F, Simeon D, Conyette L, Burney P, Seemungal T: Reduced forced vital capacity is independently associated with ethnicity, metabolic factors and respiratory symptoms in a Caribbean population: a cross-sectional study. BMC pulmonary medicine 2019, 19:1-13.

35. McEniery CM, Yasmin, Wallace S, Maki-Petaja K, McDonnell B, Sharman JE, Retallick C, Franklin SS, Brown MJ, Lloyd RC: Increased stroke volume and aortic stiffness contribute to isolated systolic hypertension in young adults. Hypertension 2005, 46:221-226.

36. Guyton AC, Hall JE: Medical physiology. Gökhan N, Çavuşoğlu H (Çeviren) 2006, 3.

37. Hislop AA: Airway and blood vessel interaction during lung development. Journal of anatomy 2002, 201:325-334.

38. Kotecha S: Lung growth for beginners. Paediatric respiratory reviews 2000, 1:308-313.

39. Maia LdA, Cruz FF, de Oliveira MV, Samary CS, Fernandes MVdS, Trivelin SdA, Rocha NdN, Gama de Abreu M, Pelosi P, Silva PL: Effects of obesity on pulmonary inflammation and remodeling in experimental moderate acute lung injury. Frontiers in immunology 2019, 10:1215.

40. Watterberg KL, Demers LM, Scott SM, Murphy S: Chorioamnionitis and early lung inflammation in infants in whom bronchopulmonary dysplasia develops. Pediatrics 1996, 97:210-215.

\section{Tables}

Table 1 Characteristics of study Participants 
Variable

\begin{tabular}{|c|c|c|c|}
\hline & & age $<10$ years & age $\geq 10$ years \\
\hline & $(n=6797)$ & $(n=1764)$ & $(n=5033)$ \\
\hline $\mathrm{Age}^{\star}$ mean $(\mathrm{SD})$ & $11.56(2.06)$ & $8.89(0.78)$ & $12.50(1.46)$ \\
\hline Males n (\%) & $3421(50.33)$ & $870(49.32)$ & 2551(50.69) \\
\hline Height $^{\star}$ mean (SD) & $153.97(12.59)$ & $140.91(8.25)$ & $158.55(10.46)$ \\
\hline Weight ${ }^{\star}$ mean (SD) & $48.42(15.58)$ & $37.15(10.66)$ & $52.38(15.10)$ \\
\hline $\mathrm{BMI}^{*} \mathrm{n}(\%)$ & $20.01(4.66)$ & $18.48(3.86)$ & $20.54(4.80)$ \\
\hline Low birth weight n (\%) & 210 (3.09) & $50(2.83)$ & $160(3.18)$ \\
\hline Premature birth n (\%) & $340(5.00)$ & $88(4.99)$ & $252(5.01)$ \\
\hline Breast fed ${ }^{*} n(\%)$ & $4792(70.50)$ & $1181(66.95)$ & 3611 (71.75) \\
\hline Person area mean (SD) & $22.73(9.78)$ & $23.11(10.03)$ & $22.60(9.69)$ \\
\hline Play time mean (SD) & $7.60(7.82)$ & $8.045(7.80)$ & $7.44(7.82)$ \\
\hline $\begin{array}{l}\text { Parent education } \geq \text { high school }{ }^{*} n \\
(\%)\end{array}$ & $4241(62.40)$ & $1214(68.82)$ & $3027(60.14)$ \\
\hline \multicolumn{4}{|l|}{ Income* n (\%) } \\
\hline$<5000 \mathrm{RMB}$ & $766(11.27)$ & $186(10.54)$ & $580(11.52)$ \\
\hline 5000-10,000 RMB & $890(13.09)$ & $208(11.79)$ & $682(13.55)$ \\
\hline $10,000-30,000 \mathrm{RMB}$ & $2411(35.47)$ & $606(34.35)$ & $1805(35.86)$ \\
\hline $30,000-100,000$ RMB & $2451(36.06)$ & $685(38.83)$ & 1766 (35.09) \\
\hline$>100,000 \mathrm{RMB}$ & $279(4.10)$ & $79(4.48)$ & $200(3.97)$ \\
\hline Smoke n (\%) & $3308(48.67)$ & $881(49.94)$ & $2427(48.22)$ \\
\hline Home renovation n (\%) & $2438(35.87)$ & $657(37.24)$ & 1781 (35.39) \\
\hline Home coal use $n(\%)$ & $682(10.03)$ & $129(7.31)$ & $553(10.99)$ \\
\hline Parent responders n (\%) & $6340(93.28)$ & $1631(92.46)$ & $4709(93.56)$ \\
\hline Family history of asthma $\mathrm{n}(\%)$ & $495(7.28)$ & $125(7.09)$ & $370(7.35)$ \\
\hline Family history of hypertension ${ }^{*} \mathrm{n}(\%)$ & $2616(38.49)$ & $728(41.27)$ & $1888(37.51)$ \\
\hline $\mathrm{SBP}^{\star}$ mean $(\mathrm{SD})$ & $112.50(13.18)$ & $106.00(10.85)$ & $114.79(13.16)$ \\
\hline
\end{tabular}




\begin{tabular}{|llll}
\hline DBP $^{*}$ mean (SD) & $64.66(9.30)$ & $63.95(9.61)$ & $64.93(9.18)$ \\
\hline Hypotensive $^{*} \mathrm{n}(\%)$ & $190(2.80)$ & $71(4.02)$ & $119(2.36)$ \\
\hline Normotensive $^{*} \mathrm{n}(\%)$ & $5712(84.04)$ & $1534(86.96)$ & $4178(83.01)$ \\
\hline Hypertensive ${ }^{*} \mathrm{n}(\%)$ & $895(13.17)$ & $159(9.01)$ & $736(14.62)$ \\
\hline $\mathrm{FVC}(\mathrm{mL})^{*}$ mean (SD) & $2626.52(753.63)$ & 2015.65 & $2840.62(726.48)$ \\
\hline FEV $(\mathrm{mL})^{*}$ mean (SD) & $2463.72(698.01)$ & $\begin{array}{l}1862.57 \\
(391.81)\end{array}$ & $2674.42658 .13)$ \\
\hline PEF $(\mathrm{mL})^{*}$ mean (SD) & $\begin{array}{l}4778.95 \\
(1411.96)\end{array}$ & $\begin{array}{l}3713.85 \\
(871.76)\end{array}$ & $5152.25(1374.48)$ \\
\hline MMEF $(\mathrm{mL})^{*}$ mean (SD) & 3349.14 & 2543.12 & $3631.65(1013.98)$ \\
\hline
\end{tabular}

FVC- Forced Vital Capacity, FEV1- Forced expiratory flow in 1 sec, PEF- Peak expiratory flow, MMEFMaximum mid expiratory flow, RMB- Chinese Yuan.

${ }^{*} \mathrm{P}<0.05$ for difference between children less than 10 years and children $\geq 10$ years by $\mathrm{t}$ test or chi-square test.

Table 2 Summary of Blood Pressure and mean Lung Function among children $<10$ and $\geq 10$ years

\begin{tabular}{lllll} 
& FVC & FEV1 & PEF & MMEF \\
\hline & Mean (SD) & Mean (SD) & Mean (SD) & Mean (SD) \\
\hline Age $<10$ years & & & & \\
\hline Hypotensive & $1869.15(652.99)$ & $1723.94(654.07)$ & $3431.27(1365.87)$ & $2394.23(985.29)$ \\
\hline Normotensive & $2032.37(721.17)$ & $1875.76(645.86)$ & $3728.07(1358.52)$ & $2550.51(999.04)$ \\
\hline Hypertensive & $1919.69(748.46)$ & $1797.23(704.88)$ & $3702.89(1451.15)$ & $2538.30(1083.00)$ \\
\hline p-value & $<.0001$ & 0.0005 & 0.0192 & 0.1305 \\
\hline Age $\geq 10$ years & & & & \\
\hline Hypotensive & $2552.94(386.50)$ & $2433.19(372.32)$ & $4911.43(915.69)$ & $3450.00(693.99)$ \\
\hline Normotensive & $2827.54(423.07)$ & $2657.53(390.01)$ & $5129.73(867.78)$ & $3606.64(631.30)$ \\
\hline Hypertensive $^{*} 2961.35(412.30)$ & $2809.28(401.34)$ & $5319.04(874.08)$ & $3802.95(679.88)$ \\
\hline p-value $^{*}$ & $<.0001$ & $<.0001$ & 0.0004 & $<.0001$
\end{tabular}


FVC- Forced Vital Capacity, FEV1- Forced expiratory flow in 1 sec, PEF- Peak expiratory flow, MMEFMaximum mid expiratory flow.

${ }^{*} p$-values are generated using Student Newman Keuls test to compare the means.

Table 3 Odds ratios of Lung function Impairment due to effects of blood pressure

\begin{tabular}{|c|c|c|c|c|}
\hline & FVC $<85 \%$ & FEV1 $<85 \%$ & $\mathrm{PEF}<75 \%$ & MMEF $<75 \%$ \\
\hline & OR $(95 \% \mathrm{Cl})$ & OR $(95 \% \mathrm{Cl})$ & OR $(95 \% \mathrm{Cl})$ & OR $(95 \% \mathrm{Cl})$ \\
\hline \multicolumn{5}{|l|}{ Age $<10$ years } \\
\hline Hypotensive & $1.04(0.49-1.98)$ & $1.54(0.72-2.97)$ & $2.31(1.17-4.23)$ & $1.39(0.68-2.59)$ \\
\hline Normotensive & 1.00 & 1.00 & 1.00 & 1.00 \\
\hline Hypertensive & $1.12(0.62-1.98)$ & $1.11(0.54-2.07)$ & $0.82(0.35-1.64)$ & $1.19(0.63-2.08)$ \\
\hline \multicolumn{5}{|l|}{ Age $\geq 10$ years } \\
\hline Hypotensive & $0.62(0.24-1.33)$ & $0.78(0.30-1.70)$ & $1.34(0.55-2.77)$ & $0.35(0.09-0.96)$ \\
\hline Normotensive & 1.00 & 1.00 & 1.00 & 1.00 \\
\hline Hypertensive & $1.03(0.80-1.32)$ & $0.98(0.73-1.30)$ & $1.13(0.82-1.53)$ & $1.05(0.80-1.36)$ \\
\hline
\end{tabular}

$\mathrm{Cl}$, confidence interval; FEV1, forced expiratory volume in 1 second; FVC, forced vital capacity; MMEF, maximum mid expiratory flow rate; $\mathrm{PEF}$, peak expiratory flow rate.

*Adjusting for age, parental education, breast feeding, low birth weight, premature birth, exercise per week, family income, home renovation, use of domestic cooking and heating fuels, environmental tobacco smoke exposure, family history of asthma and study districts.

Table 4 Absolute change estimate of lung function due to effect of blood pressure 


\begin{tabular}{|c|c|c|c|c|}
\hline & FVC & FEV1 & PEF & MMEF \\
\hline & b $(95 \% \mathrm{Cl})$ & b $(95 \% \mathrm{Cl})$ & b $(95 \% \mathrm{Cl})$ & b $(95 \% \mathrm{Cl})$ \\
\hline \multicolumn{5}{|l|}{$\begin{array}{l}\text { Age }<10 \\
\text { years }\end{array}$} \\
\hline Hypotensive & $\begin{array}{l}-206.142(-287.23 \\
-125.06)^{\star \star}\end{array}$ & $\begin{array}{l}-185.85(-259.14 \\
-112.57)^{\star \star}\end{array}$ & $\begin{array}{l}-344.90(-515.43 \\
-174.38)^{\star *}\end{array}$ & $\begin{array}{l}-195.77(-322.38 \\
-69.16)^{\star}\end{array}$ \\
\hline Normotensive & 0.00 & 0.00 & 0.00 & 0.00 \\
\hline Hypertensive & $\begin{array}{l}134.14(-200.14 \\
-68.14)^{\star *}\end{array}$ & $\begin{array}{l}-104.44(-164.08 \\
-44.79)^{\star \star}\end{array}$ & $\begin{array}{l}-56.78(-195.58, \\
82.02)\end{array}$ & $\begin{array}{l}-56.74(-159.79 \\
46.31)\end{array}$ \\
\hline \multicolumn{5}{|l|}{$\begin{array}{l}\text { Age } \geq 10 \\
\text { years }\end{array}$} \\
\hline Hypotensive & $\begin{array}{l}-493.24(-649.99 \\
-336.50)^{\star \star}\end{array}$ & $\begin{array}{l}-454.49(-594.41 \\
-314.56)^{\star \star}\end{array}$ & $\begin{array}{l}-673.46(-967.31 \\
-379.61)^{\star \star}\end{array}$ & $\begin{array}{l}-528.57(-753.59 \\
-303.55)^{\star *}\end{array}$ \\
\hline Normotensive & 0.00 & 0.00 & 0.00 & 0.00 \\
\hline Hypertensive & $\begin{array}{l}124.01(70.13 \\
177.89)^{\star \star}\end{array}$ & $\begin{array}{l}143.48(86.39 \\
182.58)^{\star \star}\end{array}$ & $\begin{array}{l}164.45(63.45 \\
265.46)^{\star \star}\end{array}$ & $\begin{array}{l}177.61(100.26 \\
254.96)^{\star *}\end{array}$ \\
\hline \multicolumn{5}{|c|}{$\begin{array}{l}\mathrm{Cl} \text {, confidence interval; FEV1, forced expiratory volume in } 1 \text { second; } \mathrm{FVC} \text {, forced vital capacity; MMEF, } \\
\text { maximum mid expiratory flow rate; } \mathrm{PEF} \text {, peak expiratory flow rate. }\end{array}$} \\
\hline \multicolumn{5}{|c|}{${ }^{\star \star} P \leq 0.001$ and ${ }^{*} P \leq 0.01$ for the difference between the change from the reference group. } \\
\hline \multicolumn{5}{|c|}{$\begin{array}{l}\text { Adjusted for age, parental education, breast feeding, low birth weight, premature birth, exercise per week, } \\
\text { family income, home renovation, use of domestic cooking and heating fuels, environmental tobacco } \\
\text { smoke exposure, family history of asthma and study district. }\end{array}$} \\
\hline
\end{tabular}

This is a list of supplementary files associated with this preprint. Click to download.

- SupplementalMaterialMoYang.docx 